\title{
COMPARING AND CONTRASTING SUSTAINABILITY PLANS FOR TAKING THEIR CAMPUSES GREEN: A TALE OF TWO INSTITUTIONS
}

\author{
Kelli N. R. Stephens ${ }^{1}$, \& Alice E. Stephens ${ }^{2}$ \\ ${ }^{1}$ Facilities Management and Planning, Hunter College (USA) \\ ${ }^{2}$ Department of Mass Media Arts, Clark Atlanta University (USA)
}

\begin{abstract}
Institutions of higher education have the potential to function as change agents for sustainability. (Stephens, Hernandez, Roman, Graham \& Scholz, 2013) According to the University Leaders for a Sustainable Future sustainability implies that the critical activities of institutions of higher education are ecologically sound, socially just, and economically viable. These institutions can function as sustainable communities, embodying responsible consumption of food and energy.

From improving recycling efforts to increasing energy efficiency and reducing waste, Hunter College is resolutely committed to sustainable actions and practices on its path towards sustainability. Through the leadership, guidance, and support of the Sustainable CUNY (City University of New York) program, Hunter College has set progressive targets, made notable gains, and pursued innovative solutions all towards the culmination of providing a healthier, cleaner, and more sustainable environment for the Hunter community. Hunter College doubled down on its commitments as the first institution within the CUNY network to promote and cultivate a position solely dedicated to advancing the College's sustainability cause. Renewed emphasis on engagement and equal representation has led the College toward creation of a new 10-Year Sustainability Action Plan led by a committee of members from the student body, faculty, and administration.

In 2010 Clark Atlanta University, an HBCU took an important step toward reversing global warming when the university's president signed the American College and University President's Climate Commitment (ACUPCC) thus joining over 600 institutions in 50 states in the United States to commit to attaining carbon neutrality. Goals were defined and outlined in the institution's Strategic Plan Initiative that set the university on a path for $20 \%$ reduction of energy consumption across the campus in five years and a doubling the campus recycling efforts by 2015 thus ensuring that sustainability issues remained an integral part of the CAU experience.

This presentation will compare and contrast the program planning for sustainability at two institutions of higher education, a public urban college in the northeastern United States and a private HBCU (Historically Black College and University) in the southeastern U.S. The presentation will describe the approaches used, progress and anticipated outcomes for each institution. How these institutes take their respective campuses green in terms of their sustainability plans and polices can be instructive for other institutions in their quest for green campuses.
\end{abstract}

Keywords: Sustainability, green campuses, institutions of higher education, urban, HBCU.

\section{Introduction}

Institutions of higher education have the potential to function as change agents for sustainability. (Stephens, Hernandez, Roman, Graham \& Scholz, 2013) According to the University Leaders for a Sustainable Future sustainability implies that the critical activities of institutions of higher education are ecologically sound, socially just, and economically viable. These institutions can function as sustainable communities, embodying responsible consumption of food and energy. 


\section{The Hunter Story}

As a public division of the City University of New York (CUNY) network, Hunter College-CUNY is a premier urban institution of higher education. The College is privileged with its standing as an enthusiastic advocate for sustainability, with a long history of early implementation and achievements in mitigating pollution, improving environmental health, and reducing emissions. Following the introduction of green campus reporting into the Princeton Review survey portfolio, Hunter College has been included in every annual edition of the Princeton Review's Guide to 399 Green Colleges since 2014.

Hunter's program planning for sustainability is guided by the policies and standards set by CUNY, as well as the practices that are directly established and managed by the Hunter administration.

Through the leadership, guidance, and support of the Sustainable CUNY (City University of New York) program, Hunter College has set progressive targets, made notable gains, and pursued innovative solutions all towards the culmination of providing a healthier, cleaner, and more sustainable environment for the Hunter community. Hunter College doubled down on its commitments as the first institution within the CUNY network to promote and cultivate a position solely dedicated to advancing the College's sustainability cause. Renewed emphasis on engagement and equal representation has led the College toward creation of a new 10-Year Sustainability Action Plan led by a council of members from the student body, faculty, and administration.

The objective of Hunter College's most recent edition of its Sustainability 10-Year Action Plan was to align the campus with the priorities of the College's Strategic Plan, as well as reaffirm the commitments and expressed values made in the College's 2008 sustainability mission statement. In 2008, Hunter created its first ever 10-Year Sustainability Action Plan, and set bold and aggressive targets to reflect the college's purpose-driven commitment and role in putting thoughts into action, engaging across the interdisciplinary spectrum, and remaining an enduring resource of innovation and collaboration.

Hunter's 2018 Sustainability Action Plan revisited the campus' 2008 sustainability goals and objectives and built on off the successes and challenges encountered to redefine strategy, reassign priorities, and rebrand the rhetoric to set new sustainability targets for the next ten years that promote Hunter College as a green institution and forum for interdisciplinary education and student success.

The 2018 Action Plan creates a pathway to chart the College's progress over the next ten years within seven designated sustainability pillars: energy, waste \& recycling, water, transportation, procurement, education \& outreach, and sustainable nutrition.

\subsection{Energy}

Hunter College's energy performance is driven in alignment with two NYC energy-saving directives that call upon the College to respectively lower its GHG emissions and energy use intensity (EUI) by a target year. Sustainable CUNY is an instrumental force in facilitating the implementation of strategies and practices that deliver on these directives and streamline both energy efficiency and optimal performance. Together with Hunter Facilities and Capital Planning Departments, all opportunities to regularly carry out mechanical equipment upgrades, replacements, and retrofits that lower energy consumption in building operations are leveraged. Over the past ten years, the College has saved over $\$ 20 \mathrm{M}$ in energy costs, and in a continued practice, the College prioritizes using every dollar saved to go directly back into the operating budget.

Solar panels were installed on the roof of Hunter's 68th Campus North Building to provide students with a living laboratory to learn, study, and observe the impacts and operations of renewables and energy efficiency, and the College also participates in the New York Power Authority's "Peak Load Management" program. Under the terms of this program, the College scales back its electricity usage on up to 15 of the hottest days of summer, helping relieve the heavy demands that are placed on the regional power grid during those times.

\subsection{Waste \& recycling}

The strategic objectives for Hunter College Waste \& Recycling are inspired by the endeavor to demonstrate and emphasize the College's alignment with New York City's zero waste commitment goals. In 2015, the Mayor of the City of New York set a citywide target to achieve at least $90 \%$ waste diversion from landfill by the year 2030, in a campaign marketed as "20 by 30 ". Hunter College's sustainability goals are marked by a renewed focus on increasing the waste diversion rate, promoting lower consumption practices, and expanding the campus-wide recycling options. Hunter College's primary waste and recycling hauler is the New York City Department of Sanitation (DSNY), therefore all items accepted for recycling by DSNY are also accepted items for recycling at Hunter College. 
The full breadth of Hunter's recycling program is affected by the changes and decisions that take place at the DSNY city agency level. As a direct College-organized practice, the Hunter Department of Environmental Health and Safety (EHS) recycles household batteries, and coordinates the responsible recycling efforts for College-owned electronics, such as laptops, desktops, and printers.

The battery recycling endeavor is a program open to all members of the Hunter campus community and all faculty, staff, and students alike are invited and encouraged to bring in their used batteries.

\subsection{Water}

Hunter College's Water objectives are undeniably impacted by the College's urbanized landscape. Opportunities to lower the water consumption attributed from building operations, as well as reduce storm water runoff are recognized as priorities for the College. As a commuter campus situated in the heart of New York City, Hunter College is without the significant presence of grounds and landscaping maintenance often seen at higher education institutions. The depth of Hunter's water conservation and efficiency efforts lies in the installation and operation of high-efficiency plumbing fixtures (such as sinks and toilets) and mechanical/HVAC equipment. Once an obsolete plumbing fixture has reached the end of its capital use cycle, Hunter College Facilities prioritizes replacement with high-efficiency plumbing fixtures. In 2010, with the advocacy of its student body, Hunter College also began (and continues to this day) installing water bottle-filling stations throughout the campus.

\subsection{Transportation}

The objectives for Hunter College Transportation are influenced by Hunter College's existing integration with New York City's mass subway transit system! As a testament to Hunter's continued advocacy and active support of mass transit, all of Hunter College's campus properties are purposely sited to nearby accessible modes of public transportation. To continue minimizing the extent of Hunter's transit-related "footprint", bicycle racks are available at each campus, and no parking spaces are made available to students, faculty, and staff. In 2018, Hunter partnered with Citibike to erect a bike-share hub at its $68^{\text {th }}$ Street Campus for use by the Hunter community and greater public. Citibike is a local bicycle-sharing program network operated by New York City.

\subsection{Procurement}

Hunter College sustainable procurement opportunities are manifests through Hunter's relationship with CUNY, as well as compliance with a State-driven Executive Order. As a public division of CUNY, many campus commodity assets (such as technology, appliances, building materials, etc.) are procured from pre-designated vendors and contracts on the CUNY inventory. Under a New York State Executive Order, Hunter is also encouraged to prioritize the purchase of products that meet environmentally preferable qualifications and performance. The planning objectives for this sustainability pillar are driven by a resolute commitment to deliver actionable progress towards purchasing green products, incorporating the use of more sustainable materials, and implementing a paperless procurement process.

\subsection{Education \& outreach}

The planning objectives for Hunter College Sustainable Education and Outreach are made with the overall strategy to engage with student government more, and to work toward creation of a shared suite of resources that will deliver on facilitating engagement and bringing keen awareness throughout the campus community on the importance of sustainability.

\subsection{Sustainable Nutrition}

The 68th Street Hunter West Cafeteria and vending machines represent the primary areas of opportunity for sustainable nutrition options at Hunter College. CUNY provides language and guidelines for food service operations is the most apt party able to take the mantle on incorporating more sustainable guidelines into food service requirements. The objectives for Hunter College Sustainable Nutrition are shaped by a renewed emphasis on the provision of organic foods, locally-sourced ingredients, and return to eco-friendly packaging. To address the elements of accessibility and affordability for sustainable nutrition, Hunter College directly established the Purple Apron service to feature as a welcome addition for the College. The Purple Apron is a free resource for undergraduate and graduate students to twice weekly receive a free bag of groceries stocked with balanced options of dairy, fruit, vegetables, grains, and protein. 


\section{The Clark Atlanta University story}

Sustainability implies that the critical activities of a higher education institution are (at a minimum) ecologically sound, socially just, and economically viable, and that they will continue to be so for future generations. A truly sustainable college or university would emphasize these concepts in its curriculum and research, preparing students to contribute as working citizens to an environmentally sound and socially just society. The institution would function as a sustainable community, embodying responsible consumption of food and energy, treating its diverse members with respect, and supporting these values in the surrounding community.

As the nation's oldest historically black research institution, Clark Atlanta University (CAU) provides leadership in Historically Black Colleges and Universities (HBCU) sustainability and helps to foster emerging geoscience networks. CAU is on the cutting edge advancing diversity, equity and inclusion.

In 2010 Clark Atlanta University took an important step toward reversing global warming when the university's president signed the American College and University President's Climate Commitment (ACUPCC) thus joining over 600 institutions in 50 states in the United States to commit to attaining carbon neutrality. Goals were defined and outlined in the institution's Strategic Plan Initiative that set the university on a path for $20 \%$ reduction of energy consumption across the campus in five years and a doubling the campus recycling efforts by 2015 thus ensuring that sustainability issues remained an integral part of the CAU experience.

As described in its 2018 Annual Sustainability Report the CAU Campus Sustainability Plan is a dynamic document intended to provide a roadmap for advancing sustainability over the next five years (2018 - 23). The Plan identifies leadership, organization and resources as the key ingredients for moving CAU sustainability forward. The Sustainability Plan invited feedback and creative suggestions from CAU Trustees, administration, faculty and students. The plan is considered a living document that will guide sustainability efforts of the university from 2018-2023.

Success means that older materials, facilities and habits are replaced with more sustainable options. As this transition takes place there are positive impacts on health, well-being and the natural environment. Most often the changes are subtle. The appearance of bicycles and bike racks on campus is now well integrated in the CAU fabric as are electric powered golf carts. Ultimately, small changes like the bikes, carts and bottle-less water stations change habits. Behavioral change is one of our most important sustainability goals.

\subsection{Sustainability principles that guide the CAU Plan have been adopted in five categories}

3.1.1. Leadership. Integrating environmental concerns into decision making at CAU involves providing students, faculty, and employees with opportunities to become environmentally aware; promoting environmental leadership as a continuous and participatory process; using university leadership and expertise to assist local environmental efforts. CAU housed the Building Green Initiative, AUC Vine City \& English Avenue (AVE) EcoDistrict, co-leads the HBCU Geoscience Working Group with FAMU, and launched the HBCU Green Fund, all innovative green initiatives and ideas that matter.

3.1.2. Engagement. CAU has implemented procedures to minimize its impact on the environment by developing a sustainability plan that outlines efforts to limit its negative impact on the environment. Part of this engagement includes revising policies and procedures to promote sustainability, and strategies to reuse and recycle.

3.1.3. Education. This principle focuses on changes in behavior and the raising of awareness of sustainability on campus and in the community. CAU has maintained a leadership role in the national HBCU Geosciences Working Group and the NSF funded InTeGraTe (Interdisciplinary Teaching about Earth for a Sustainable Future) project. Several CAU faculty members participated in InTeGrate Traveling Workshops focused on topics of concern to HBCUs including Strengthening Geoscience Competency for HBCU Pre-Service Teachers, Putting Sustainability into Action and Pan-African Approaches in Teaching Geosciences. The Sustainability \& Social Justice Workshop held in the spring at CAU had the goal of advancing curriculum development around themes and pedagogy for sustainability $\&$ social justice for CAU and regional faculty.

3.1.4. Research. A principle at $\mathrm{CAU}$ is to incorporate sustainability into research efforts at the university and use research to advance sustainability programs. The aim is that research at the university should be conducted in an environmentally responsible way. Research funds should be utilized to help the university obtain sustainability. Faculty expertise should be used to help promote sustainability efforts. 
3.1.5. Campus. The goal is to involve the university community and the community surrounding the institution in the sustainability process. This includes developing projects such as a community garden and other microenterprises that help the local community, and celebrating CAU's successes within the community. CAU is an active participant in the new Greater-Atlanta Regional Center of Expertise (RCE) a network of multidisciplinary stakeholders, including higher education institutions, businesses, non-governmental organizations, community associations, and local, regional, state and federal government agencies coming together to address environmental challenges, climate change, resilience and sustainable development goals.

\section{Conclusion}

How these institutes, Hunter College and the HBCU, Clark Atlanta University (CAU) took their respective campuses green in terms of their sustainability plans and polices can be instructive for other institutions of higher education in their quest for green campuses.

Hunter College's mission includes striving to integrate the principles of sustainability in all business decisions including the following: Consulting with all campus stakeholders to identify sustainability goals and promote their achievement; Measuring and reporting on campus sustainability initiatives; Evaluating and redesigning all our operations to reduce their environmental impact; Developing educational and research agendas to meet the long-term goals of sustainability; Promoting awareness about the consumption of natural resources by individuals and groups; Encouraging environmentally sound practices among students, faculty and staff; and Seeking strategic collaborations with other organizations to advance the college's sustainability goals.

CAU is a member of AASHE (The Association for the Advancement of Sustainability in Higher Education) and has been able to purposefully leverage the breadth of resource and engagement opportunities that this association has provided. AASHE is dedicated to inspiring higher education to lead the sustainability transformation. However, issues of resources for smaller institutions impede implementation of its sustainability goals and initiates. CAU's success with this endeavor identifies a potential opportunity for which Hunter College could also take advantage.

\section{References}

Archer, R. S., Davis, F., Ebanks, S. C., \& Gragg, R. D. S. (2019). HBCUs Broadening Participation in Geosciences (A Journey Through InTeGrate). In Interdisciplinary Teaching About Earth and the Environment for a Sustainable Future (pp. 361-378). Springer, Cham.

Stephens, J. C., Hernandez, M. E., Román, M., Graham, A. C., \& Scholz, R. W. (2008). Higher education as a change agent for sustainability in different cultures and contexts. International Journal of Sustainability in Higher Education, 9(3), 317-338. 